\title{
Prevalence of low bone mass and changes in vitamin D levels in human immunodeficiency virus-infected adults unexposed to antiretrovirals
}

\author{
Nathalia Sernizon Guimarães $[1]$, Milena Maria Moreira Guimarães ${ }^{[2]}$, \\ Adriana Maria Kakehasi ${ }^{[3]}$, Mariana Guimarães Penido de Paula ${ }^{[1]}$, \\ Júlia Fonseca de Morais Caporali ${ }^{[1],[2]}$, Érica Leandro Marciano Vieira ${ }^{[1]}$, \\ Pedro Rezende Tanajura ${ }^{[1]}$ and Unaí Tupinambás ${ }^{[1],[2]}$
}

[1]. Programa de Pós-Graduação Strictu Senso em Ciências da Saúde: Infectologia e Medicina Tropical, Universidade Federal de Minas Gerais, Belo Horizonte, MG, Brasil.

[2]. Departamento de Clínica Médica, Universidade Federal de Minas Gerais, Belo Horizonte, MG, Brasil.

[3]. Departamento de Aparelho Locomotor, Universidade Federal de Minas Gerais, Belo Horizonte, MG, Brasil.

\begin{abstract}
Introduction: The prevalence of low bone mass is 3 times higher in people living with human immunodeficiency virus (PLWH) and using antiretrovirals than in the HIV-unaffected population. Changes in vitamin D levels is one of the factors associated with decreased bone mass. The objective of this study is to evaluate the low bone mass and altered vitamin D levels in PLWH who have not been exposed to antiretrovirals. Methods: A cross-sectional study was carried out with HIV-infected individuals between the ages of 18 and 55 years immediately prior to the start of antiretroviral therapy in a specialized reference center focusing on infectious and parasitic diseases. Results of clinical examination (patient's weight, height, blood pressure, and clinical history), laboratory tests, and X-ray absorptiometry, were collected. Results: Sixty patients were included, with a mean age of 34 years. Nine (16.7\%) patients presented with low bone mass and 4 (7.1\%) patients showed low total femur BMD. Analysis revealed that $23.3 \%$ and $36.7 \%$ of the patients had deficient and insufficient levels of 25 -hydroxyvitamin D3, respectively. Conclusions: Our study population presented with compromised bone health and with low bone mineral density and 25-(OH)-vitamin D levels.
\end{abstract}

Keywords: Bone mass. Vitamin D. HIV. People living with HIV. Biomarker.

\section{INTRODUCTION}

Due to the increased survival associated with antiretroviral treatment (ART), people living with human immunodeficiency virus (PLWH) are increasingly affected by the complications of chronic infection as well as of the prolonged use of antiretrovirals $(\mathrm{ARVs})^{1,2}$. Metabolic changes associated with ARV use such as dyslipidemia, insulin resistance, lipodystrophy, and alterations in mineral and bone metabolism have been described ${ }^{3-6}$.

The prevalence of low bone mineral density in PLWH receiving ARVs is 3 times higher $(28 \%-50 \%)$ than in the HIV-unaffected population $(16 \%)^{7,8}$. Non-traditional causes of low bone mass include the direct effects of ARVs and the chronic activation of the immune system due to viral infection? Hypogonadism, smoking status, alcoholism, low body mass

Corresponding author: $\mathrm{Dr}^{\mathrm{a}}$ Nathalia Sernizon Guimarães

e-mail: nasernizon@gmail.com

Received 18 December 2017

Accepted 30 July 2018 index, imbalance of nutrients in the diet, and changes in vitamin D levels are also associated with decreased bone mass ${ }^{9-12}$.

Insufficiency or deficiency in plasma vitamin D levels have reached epidemic proportions, even in tropical regions ${ }^{13}$. Vitamin D status is not determined by the measurement of serum 1,25-dihydroxyvitamin $\mathrm{D}$ concentrations; it is assessed by measuring the prohormone 25 -hydroxyvitamin D3 $(25-\mathrm{OH}$ D3), which is an indicator of supply rather than function. 25OH D3 is the most stable and plentiful metabolite of vitamin D in human serum, and has a half-life of approximately 3 weeks, making it the most suitable indicator of vitamin D status. In the past, vitamin $D$ deficiency was identified by the presence of bone disease, either rickets or osteomalacia ${ }^{13,14}$. Bone diseases caused by vitamin D deficiency are associated with serum $25-\mathrm{OH}$ D3 values of below $10 \mathrm{ng} / \mathrm{ml}$. More recently, the term vitamin D insufficiency has been used to describe suboptimal levels of serum 25-OH D3, which may be associated with other disease outcomes. It is still debatable whether vitamin D deficiency or insufficiency can be defined precisely on the basis of 25-OH D3 concentration. A cutoff value of $30 \mathrm{ng} / \mathrm{mL}$ is sometimes used for defining optimal vitamin status. Many patients have been 
diagnosed with vitamin $\mathrm{D}$ deficiency or insufficiency based on measurement of 25-OH D3 concentrations, even when most of them have no evidence of disease ${ }^{14-15}$.

Investigators have considered various functional measures to assess the adequacy of vitamin D status ${ }^{16,17}$. One functional definition of optimal vitamin D status is the 25-OH D3 level that maximally suppresses parathyroid hormone (PTH) secretion, because a low level of serum ionized calcium is the major stimulus for PTH secretion. In adults, multiple cross-sectional examinations of the relationship between serum PTH and 25-OH D3 levels demonstrated a plateau in the suppression of PTH when the $25-\mathrm{OH}$ D3 level reaches approximately $30 \mathrm{ng} / \mathrm{mL}^{18}$. This is the rationale for selecting $30 \mathrm{ng} / \mathrm{mL}$ as the cutoff value for defining optimal vitamin $\mathrm{D}$ status. However, this definition represents an average value at a population level but does not account for the wide variation in the 25-OH D3 level that represents adequacy at an individual level. Many patients have very low 25-OH D3 values without any evidence of increased PTH production, and conversely, 25-OH D3 levels greater than $30 \mathrm{ng} / \mathrm{mL}$ do not guarantee PTH suppression ${ }^{18}$.

Observational studies have reported very high incidence rates of low 25-OH D3 levels in both the general and HIV-infected populations ${ }^{5,19,20}$. Among the possible reasons for this clinical condition are low sun exposure, black race, obesity, sedentary lifestyle, malabsorption, renal or hepatic alterations, smoking, injecting drug use, advanced age, factors directly related to HIV, and exposure to ARVs ${ }^{19,20}$. Both vitamin D and agents used to treat HIV and opportunistic infections are metabolized via the cytochrome $\mathrm{P} 450$ system $^{21}$; this creates a potential for metabolic interactions that could alter the effectiveness of standard vitamin D replacement strategies. For example, the protease inhibitor and nonnucleoside reverse transcriptase inhibitor classes of ARV agents have been linked to 1,25-dihydroxyvitamin D deficiency; these drugs accelerate the hydroxylation of vitamin D and its metabolites to form non-biologically active compounds ${ }^{22,23}$. Due to the complex interactions of host response, chronic infection, and inflammation, and the metabolic consequences of ART, HIVinfected persons could be predicted to have unique risk factors for low 25-OH D3 levels. For example, both obesity and low body weight have been associated with vitamin $\mathrm{D}$ deficiency in PLWH ${ }^{24,25}$. Other HIV-specific factors such as current or nadir cluster of differentiation 4 (CD4) count, HIV-1 viral load, and stage of disease have also been inconsistently associated with low 25-OH D3 levels to date ${ }^{24,25}$. Viard et a ${ }^{26}$ assessed the rates of disease progression in PLWH and demonstrated that PLWH with high levels of vitamin $\mathrm{D}$ had a lower risk of disease progression to AIDS than those with low vitamin D levels ${ }^{26}$.

Given this context we aimed to evaluate the bone mass and changes in vitamin D levels in PLWH who were not receiving ARVs.

\section{METHODS}

A cross-sectional study involving adults living with HIV immediately prior to the start of ART was carried out in a specialized reference center focused on infectious and parasitic diseases between 2014 and 2015.

HIV-infected individuals of both sexes between the ages of 18 and 55 years who were not yet exposed to ARVs were eligible for this study, regardless of the time of HIV diagnosis and prior use of calcium or vitamin D supplements. Patients using corticosteroids or patients who were previously diagnosed with other pathological conditions that could alter bone metabolism (neoplasms and renal or hepatic insufficiency) were excluded from the study.

\section{Ethical considerations}

This project was approved by the ethics committee of the Federal University of Minas Gerais, under the number 389.763.

Data collection was performed in the following 3 steps: clinical evaluation, laboratory tests (blood/plasma and urine samples), and dual-energy X-ray absorptiometry. For clinical examination, information on weight, height, blood pressure, clinical history, date of HIV diagnosis, and family history were collected. After a 12-hour fast and clinical consultation, blood/plasma and urine samples were collected from the patients. Tests were performed for complete blood count, CD4+ lymphocyte counts, and viral load as well as for measurement of D-dimer, fibrinogen, 25-OH D3, PTH, calcium, phosphorus, and potassium levels. The complete blood count was determined by flow cytometry using the CELL-DYN Ruby analyzer (Abbott Core Laboratory: Abbott $\mathrm{C}$, Abbott Park, Illinois, USA) Diagnostics D-dimer concentrations were measured using quantitative enzyme-linked immunosorbent assay (ELISA). Fibrinogen levels were evaluated using a coagulometric method. The level of 25-OH D3 was measured by the chemiluminescence method using a commercial $25-\mathrm{OH}$ D3 kit and automatic analyzer (Cobas 6000, model E601, Roche Diagnostics ${ }^{\circledR}$ Risch-Rotkreuz, Suíça). The cutoff levels for vitamin D insufficiency and deficiency were $21-29 \mathrm{ng} / \mathrm{ml}$ and $\leq 20 \mathrm{ng} / \mathrm{ml}$, respectively ${ }^{14,15}$. PTH levels were evaluated using the Human Bone Metabolism Kit (Merck Millipore ${ }^{\circledR}$, Brazil). The concentrations of calcium, phosphorus, and potassium were measured by the colorimetric method using Vitros 5600/Vitros 5.1 FS (Orthoclinical Diagnostics [Johnson ${ }^{\odot}$, Brazil]). The CD4+ T lymphocyte count was determined by flow cytometry using the Multitest ${ }^{\circledR}$ Kit and the viral load was determined by chemiluminescence using the Versant ${ }^{\circledR}$ HIV-1 RNA 3.0 Kit.

Dual-energy X-ray absorptiometry was performed using the Discovery W Dual-Energy X-ray Absorptiometer (Hologic Inc., Waltham, Massachusetts, USA), and evaluated using APEX 3.3 software (Hologic Inc., Waltham, Massachusetts, USA). The bone mass measurement [bone mineral density [BMD]) was interpreted according to the recommendations of the International Society for Clinical Densitometry 2013 criteria $^{27}$. BMD was evaluated for the lumbar spine (between the L1 and L4 vertebrae), femoral neck, and total femur using standardized positioning techniques. BMD was expressed in $\mathrm{g} /$ $\mathrm{cm}^{2}$ and in Z-score and T-score values, according to the age of the patient ${ }^{28,29}$. Low bone mass was defined by a Z-score $\leq-2.0$ in patients younger than 50 years ${ }^{29}$.

The categorical data collected was described as frequency and percentage whereas numerical data was described by means of central tendency (mean or median) and dispersion measures (standard deviation or $25^{\text {th }}$ and $75^{\text {th }}$ percentiles), respecting the normality test (Shapiro-Wilk) of the distribution of these variables. 
Continuous variables with normal distribution were compared using the Student's t-test; continuous variables with non-normal distribution were compared using the Wilcoxon test. The difference between the means was evaluated by analysis of variance (ANOVA). The frequencies were compared using the Chi-Square or Fisher test, whichever appropriate.

We used the Spearman's correlation test to analyze the association between the quantitative variables of the study. For all the statistical tests applied, a significance level of 5\% was considered.

\section{RESULTS}

Sixty patients were included in the study, with a mean age of 34 years (range, $19-55$ years). Of the 60 patients, $48(80 \%)$ were men, $39(65 \%)$ had completed more than 10 years of schooling, and $29(48 \%)$ were black or brown. Of the 60 patients, changes in 25-OH D3 levels were observed in $36(60 \%)$ patients, of which $14(23.3 \%)$ showed deficiency and $22(36.7 \%)$ showed insufficiency. The median time to HIV diagnosis was 19 months [95\% confidence interval (95\% CI), 19.5-20]. Sexual contact $(95 \%)$ was the main cause of HIV transmission; of these, 47 (63\%) patients acquired the infection through homo/bisexual relationships. Ten (17\%) patients were smokers, $5(7 \%)$ had hypertension, and $4(6.7 \%)$ had pre-existing dyslipidemia. Three (5\%) patients reported alcohol abuse and $42(70 \%)$ patients reported making use of alcohol in a "social" way.

The median viral load was 40.610 copies/ml (95\% CI, 16.360-101.069) and median CD4+ lymphocyte count was 439 cells $/ \mathrm{mm}^{3}$ (95\% CI, 258-543). Based on clinical categories ${ }^{30}$, 51 patients were asymptomatic (97\%). According to the BMI classification, $18(30 \%)$ of 60 patients were overweight or obese based on the anthropometric variables collected (weight and height $)^{31}$. Table 1 describes the prevalence of spinal BMD (L1-L4), femoral neck BMD, and total femur BMD deficiencies as well as the bone markers evaluated in the study population $(\mathrm{n}=60)$. The prevalence of low spinal BMD (L1-L4) and total femur BMD were $16.7 \%$ and $7.1 \%$, respectively .
The mean and median creatinine clearance levels were ${ }^{27}$ estimated to be $119.57 \mathrm{ml} / \mathrm{min}$ and $115.34 \mathrm{ml} / \mathrm{min}$, respectively. All patients had creatinine clearance values higher than 60 $\mathrm{ml} / \mathrm{min}$. Twelve patients (17.1\%) showed alterations such as hematuria, proteinuria, or glycosuria in the urine test.

Table 2 presents the description of bone metabolism markers according to the prevalence of low BMD in PLWH. There was no statistical difference between the analyzed variables $(p>0.05)$. Table 3 presents the description of bone metabolism markers according to the levels of 25-OH D3 in PLWH. It was observed that subjects with vitamin D insufficiency had decreased D-dimer levels $(p<0.05)$ compared to individuals without vitamin D insufficiency. Contrastingly, individuals having sufficient concentrations of vitamin D had significantly lower levels of fibrinogen $(p<0.05)$ than the individuals having altered vitamin D levels. There was no statistical difference between individuals who presented with and without alterations in vitamin D levels with respect to PTH, calcium, and phosphorus levels.

Table 4 shows the association between the levels of $25-\mathrm{OH}$ D3 and BMD of patients by means of Spearman's correlation.

\section{DISCUSSION}

As the main finding of this study, we observed a high prevalence $(60 \%)$ of alterations in serum levels of $25-\mathrm{OH}$ D3; in the study population, $23 \%$ and $37 \%$ of the patients showed deficiency and insufficiency of this micronutrient, respectively. Vitamin D is considered as an immunomodulator that affects several subpopulations of hematopoietic cells, such as monocytes, macrophages, and B and T lymphocytes. The role of vitamin $\mathrm{D}$ in defense mechanisms against different types of infections, including HIV infection, has been studied ${ }^{32}$. One of the most widely known defense mechanisms is through the production of cathelicidin (LL-37), a 1,25-dihydroxyvitamin D-dependent antimicrobial peptide synthesized by monocytes and activated macrophages in response to pathogenic agents

TABLE 1: Bone mineral density, markers of bone metabolismin adults living with HIV who have not been exposed ARVs (2014-2015).

\begin{tabular}{|c|c|c|c|c|c|c|c|}
\hline Variable & n & Mean & SD & Median & $\begin{array}{c}\text { Lowest } \\
\text { value }\end{array}$ & Highest value & $\begin{array}{l}\text { BMD values below } \\
\text { normal for age (\%) }\end{array}$ \\
\hline Bone mass (DXA) & 60 & & & & & & \\
\hline Total femoral BMD $\left(\mathrm{g} / \mathrm{cm}^{2}\right)$ & 60 & 0.98 & 0.14 & - & - & - & - \\
\hline Lumbar Z-score (L1-L4) & 60 & -0.78 & 1.14 & - & - & - & 16.7 \\
\hline 25-OH D3 (ng/ml) & 60 & - & - & 28.1 & 7.0 & 61.3 & 60.0 \\
\hline Calcium (mg/dl) & 60 & - & - & 9.5 & 8.6 & 11.1 & 3.3 \\
\hline Phosphorus (mg/dl) & 60 & - & - & 3.8 & 2.7 & 5.0 & 1.7 \\
\hline PTH (pg/ml) & 60 & - & - & 27.3 & 8.1 & 60.2 & 1.7 \\
\hline
\end{tabular}

HIV: human immunodeficiency virus; ARVs: antiretrovirals; $\mathbf{n}$ : adults living with HIV; SD: standard deviation; BMD: bone mineral density; DXA: dual-energy X-ray absorptiometry; 25-OH D3: 25-hydroxyvitamin D3; PTH: parathyroid hormone. Cutoff points: <29ng/ml 25-OH D3; hypocalcemia <8,6mg/dl calcium; hypophosphatemia $<3.0 \mathrm{mg} / \mathrm{dl}$ phosphate; hypoparathyroidism $<8.5 \mathrm{mg} / \mathrm{dl} \mathrm{PTH}$ 
TABLE 2: Description of bone metabolism markers according to bone mineral density in adults living with HIV who have not been exposed to ARVs (2014-2015).

\begin{tabular}{|c|c|c|c|c|c|c|c|}
\hline Variables & \multicolumn{4}{|c|}{ Unaltered } & \multicolumn{2}{|c|}{ Low bone mass } & $p^{*}$ \\
\hline \multicolumn{8}{|l|}{ Lumbar } \\
\hline vitamin D & 45 & 28.4 & 10.3 & 9 & 24.6 & 7.1 & 0.8487 \\
\hline parathyroid hormone & 45 & 28.1 & 11.2 & 9 & 20.3 & 9 & 0.9714 \\
\hline calcium & 45 & 9.4 & 0.4 & 9 & 9.5 & 0.2 & 0.4161 \\
\hline fibrinogen & 44 & 186.5 & 127 & 9 & 230 & 84.7 & 0.1659 \\
\hline D-dimer & 42 & 422.6 & 633.1 & 9 & 415.1 & 276 & 0.5138 \\
\hline \multicolumn{8}{|l|}{ Total femur } \\
\hline vitamin D & 52 & 27.3 & 8.6 & 4 & 22.1 & 10.6 & 0.8729 \\
\hline fibrinogen & 51 & 197.7 & 121.7 & 4 & 187.7 & 122.3 & 0.5626 \\
\hline D-dimer & 50 & 434.4 & 598.6 & 3 & 419.9 & 102.9 & 0.5165 \\
\hline \multicolumn{8}{|l|}{ Femur neck } \\
\hline vitamin D & 51 & 26.9 & 8.9 & 5 & 27.3 & 7.6 & 0.4689 \\
\hline parathyroid hormone & 51 & 26.6 & 10.8 & 5 & 27.8 & 15.4 & 0.4131 \\
\hline calcium & 51 & 9.5 & 0.4 & 5 & 9.7 & 0.2 & 0.1694 \\
\hline phosphorus & 51 & 4.5 & 0 & 5 & 3.8 & 0.6 & 0.1320 \\
\hline fibrinogen & 50 & 201.1 & 119.9 & 5 & 156.2 & 133.8 & 0.7837 \\
\hline
\end{tabular}

HIV: human immunodeficiency virus; ARVs: antiretrovirals; SD: standard deviation. *Student's t test.

TABLE 3: Description of markers of bone metabolism according to 25-hydroxyvitamin D3 levels in adults living with HIV who have not been exposed to ARVs (2014-2015).

\begin{tabular}{|c|c|c|c|c|c|c|c|}
\hline \multirow{2}{*}{ Variables } & \multicolumn{2}{|c|}{ Sufficiency $(n=24)$} & \multicolumn{2}{|c|}{ Insufficient $(n=22)$} & \multicolumn{2}{|c|}{ Deficiency $(n=14)$} & \multirow{2}{*}{$p^{*}$} \\
\hline & mean & SD & mean & SD & mean & SD & \\
\hline Parathyroid hormone & 29.5 & 10.9 & 25.1 & 10.3 & 9.5 & 0.3 & 0.4496 \\
\hline Calcium & 9.4 & 0.4 & 9.5 & 0.5 & 9.5 & 0.3 & 0.6335 \\
\hline Phosphorus & 4.2 & 0.3 & 3.8 & 0.6 & 3.6 & 0.9 & 0.4892 \\
\hline Fibrinogen & 132.9 & 115.2 & 232.2 & 103.2 & 219.4 & 128.3 & 0.0129 \\
\hline D-dimer & 492.1 & 829.1 & 342.3 & 240.1 & 459.7 & 337.1 & 0.0000 \\
\hline Neck BMD & 0.9 & 0.2 & 0.9 & 0.1 & 0.8 & 0.1 & 0.7903 \\
\hline Lumbar BMD & 1 & 0.1 & 0.9 & 0.1 & 0.9 & 0.1 & 0.7703 \\
\hline
\end{tabular}

HIV: human immunodeficiency virus; ARVs: antiretrovirals; SD: standard deviation; BMD: bone mineral density; *ANOVA, Bonferroni-one way. 
TABLE 4: Univariate analysis of dosage of 25-hydroxyvitamin D3 and bone mineral density of adults living with HIV who have not been exposed to ARVs (2014-2015).

\begin{tabular}{|c|c|c|c|}
\hline Lumbar BMD & 0.3322 & & $<0.0001$ \\
\hline Femoral BMD & Insufficient vit D & Lumbar BMD & \\
\hline Lumbar BMD & -0.1488 & & $<0.0001$ \\
\hline Femoral BMD & Deficient vit D & Lumbar BMD & \\
\hline Lumbar BMD & 0.0416 & & $<0.0001$ \\
\hline Femoral BMD & 0.1540 & 0.7487 & $<0.0001$ \\
\hline
\end{tabular}

HIV: human immunodeficiency virus; ARVs: antiretrovirals; SD: standard deviation; vit: vitamin; BMD: bone mineral density. *Spearman correlation.

that cause infections, including HIV. Recent studies have demonstrated the ability of LL-37 to inhibit HIV-1 replication in CD4 lymphocytes and macrophages. Hence, sub-optimal levels of vitamin $\mathrm{D}$ could affect the immune response in patients infected with $\mathrm{HIV}^{33}$.

It is known that many HIV-infected individuals have insufficient or deficient levels of vitamin D; this fact is relevant considering that vitamin D may be an inflammatory marker ${ }^{34,35}$. However, we aimed to draw attention to the mean age of the patients in the study population (34 years) as well as the absence of exposure to ART. Dark pigmentation of the skin, obesity, low sun exposure, low intake of vitamin D, injecting drug use, sedentary lifestyle, smoking, kidney disease, liver disease, and intestinal malabsorption ${ }^{15}$ are the traditional risk factors of low vitamin D levels; in addition HIV infection may reduce vitamin $\mathrm{D}$ levels by inducing the production of pro-inflammatory cytokines such as TNF- $\alpha$ which inhibits renal hydroxylation, as well as the decrease in serum levels due to the association of the activity of macrophages and lymphocytes and the progression of infection ${ }^{14}$. We should also mention the change in the reference value of 25-OH D3 serum levels: classification of insufficient vitamin $\mathrm{D}$ levels is considered absent, omitting risk values. In clinical practice, it is necessary to consider the risk factors mentioned above in addition to the serum vitamin D levels evident by laboratory examination while making the decision to use supplements to treat the symptoms of fatigue, muscular weakness, chronic pain, and possible bone fractures.

However, more studies are needed to fully define the relationship between HIV infection and vitamin D metabolism, considering that the available studies were conducted for a short time period and in a small sample population ${ }^{36}$. To date, there is no consensus on what the serum reference level should be for 25-OH D3 in PLWH. However, it is known that the lower limit should be the one that maintains normal serum calcium levels and, consequently, does not induce PTH release ${ }^{36}$. It is unclear whether HIV infection itself contributes to low BMD; however, $\mathrm{HIV}$-infected individuals have a high prevalence of risk factors for low BMD, such as poor nutrition, low body weight, high rates of tobacco and alcohol use, and low vitamin D levels. In addition, initiation of ART is associated with up to $6 \%$ reduction in BMD during the first 2 years of treatment, which varies with the specific ART medications used ${ }^{37}$.

The Z-score analysis of BMD revealed that $16.7 \%$, $9.0 \%$, and $7.1 \%$ of the patients had reductions in bone mass in the lumbar spine (L1-L4), femoral neck, and total femur, respectively. Brown et $a l^{38}$, when studying $33 \mathrm{HIV}$-infected individuals who were not using ARVs, found a lower prevalence of low BMD ( $9 \%$ lumbar spine, $1 \%$ hip, and $2 \%$ femur) than that found in our study. The importance of the data evaluated in our study is emphasized, especially since it is a population with a recent date of HIV infection diagnosis. One possible reason for the difference between these findings may be that viral proteins are able to directly stimulate osteoclastic activity and inhibit osteoblastic activity. In addition, HIV-positive patients show elevated levels of inflammatory cytokines such as interleukin- 6 and tumor necrosis factor- $\alpha$, which are capable of promoting osteoclast formation, and thus, contribute to bone reabsorption ${ }^{7,15}$.

Hileman et $a l^{34}$ demonstrated decreased BMD in $33.3 \%$ of PLWH with a median age of 40 (25-50), which is higher than the median age in our study. In agreement with our findings, the authors also did not find an association between vitamin $\mathrm{D}$ status and alterations in the BMD, although their study population had a high prevalence of vitamin D deficiency. Many previous studies have evaluated BMD in HIV-infected patients; however, unlike our study, more than $90 \%$ of the evaluated patients were receiving $\mathrm{ART}^{9,39}$.

The description of biomarker profile is necessary, especially for establishing the prognosis of these patients with low bone mass. However, the reference values are for biomarker levels are not known. The absence of a control group and the relatively small sample population are the limitations of our study. However, our results revealed that, although young 
and unexposed to ARVs, the study population presented with compromised bone health, low BMD, and low levels of 25-(OH)-vitamin D.

Therefore, we suggest that longitudinal interventions be considered in the care of PLWH of any age and at any time of infection for the prevention and early diagnosis of low BMD and vitamin D deficiency.

\section{Conflict of interest}

The authors declare that there is no conflict of interest.

\section{REFERENCES}

1. Torres TS, Cardoso SW, Velasque LS, Marins LMS, Oliveira MS, Veloso VG. Aging with HIV: an overview of an urban cohort in Rio de Janeiro (Brazil) across decades of life. Braz J Infect Dis. 2013;17(3):324-31.

2. Samji H, Cescon A, Hogg RS, Modur SP, Althoff KN, Buchacz K. Closing the gap: increases in life expectancy among treated HIVPositive Individuals in the United States and Canada. PLoS One. 2013;8(12):813-55.

3. Braga IS, Guimarães NS, De Figueiredo SM. Distúrbios nutricionais e metabólicos provocados pela utilização da terapia antirretroviral e abordagem nutricional: uma revisão narrativa. Nut Clín Diet Hosp. 2015;35(1):71-5.

4. Guimarães MMM, Greco DB, de O Júnior AR, Penido MG, Machado LJC. Corporal fat distribution and lipidic and glicemic profiles of HIV-infected patients. Arq Bras Endocrinol Metab. 2007;51(1):42-51.

5. Overton ET, Chan ES, Brown TT, Tebas P, McComsey GA, Melbourne KM, et al. Vitamin D and Calcium Attenuate Bone Loss With Antiretroviral Therapy Initiation: A Randomized Trial. Ann Intern Med. 2015;162(12):815-24.

6. Battalora L, Buchacz K, Armon C, Overton ET, Hammer J, Patel P, et al. Low bone mineral density and risk of incident fracture in HIVinfected adults. Antivir Ther. 2016; 21(1):45-54.

7. Walker-Harris V, Brown TT. Bone loss in the HIV-infected patient: evidence, clinical implications, and treatment strategies. Braz J Infect Dis. 2012;205(3):391-8.

8. Silva-Santos AC, Matos MA, Galvão-Castro B. Reabsorção no metabolismo ósseo de pacientes HIV-positivos. Acta Ort Bras. 2008;17(2):50-2.

9. Tebas P, Powderly WG, Claxton S, Marin D, Tantisiriwat W, Teitelbaum SL, et al. Accelerated bone mineral loss in HIV infected patients receiving potent antiretroviral therapy. AIDS. 2000;14(4):63-7.

10. Casado JL, Bañon S, Andrés R, Perez-Elías MJ, Moreno A, Moreno $\mathrm{S}$. Prevalence of causes of secondary osteoporosis and contribution to lower bone mineral density in HIV-infected patients. Osteoporosis Int. 2014;25(3):1071-9.

11. Altuntas O, Kumbasar H, Karahasanoglu R. Prevalence and risk factors of osteopenia / osteoporosis in Turkish HIV/AIDS patients. Braz J Infect Dis. 2013;17(6):707-11.

12. Compston J. Osteoporosis and fracture risk associated with HIV infection and treatment. Endocrinol Metabol Clin. 2014;43(3):769-80.

13. Conrado T. Vitamin D Deficiency in HIV-Infected Women on Antiretroviral Therapy Living in the Tropics. J Int Assoc Provid AIDS Care. 2011;10(4):239-45.
14. Lake JE, Adams JS. Vitamin D in HIV-infected patients. Current HIV/AIDS. 2011;8(3):133-41.

15. Escota GV, Cross S, Powderly WG. Vitamin D and calcium abnormalities in the HIV-infected population. Endocrinol Metabol Clin. 2014;43(3):743-67.

16. Kennel KA, Drake MT, Hurley DL. Vitamin D deficiency in adults: when to test and how to treat. Mayo Clin Proc. 2010;85(8):752-7.

17. Prentice A, Goldberg GR, Schoenmakers I. Vitamin D across the lifecycle: physiology and biomarkers. Am J Clin Nutr. 2008;88(2):500-6.

18. Chapuy MC, Preziosi P, Maamer M, Arnaud S, Galan P, Hercberg $\mathrm{S}$, et al. Prevalence of vitamin D insufficiency in an adult normal population. Osteoporos Int. 1997;7(5):439-43.

19. Jiménez-Sousa MÁ, Martínez I, Medrano LM, FernándezRodríguez A, Resino S. Vitamin D in human immunodeficiency virus infection: influence on immunity and disease. Front Immunol. 2018;9:458.

20. Mansueto P, Seidita A, Vitale G, Gangemi S, Iaria C, Cascio A. Vitamin D deficiency in HIV infection: not only a bone disorder. Biomed Res Int. 2015;2(1):1-18.

21. Villamor E. A potential role for vitamin D on HIV infection? Nutr Rev. 2006 64(5):226-33.

22. Cozzolino M, Vidal M, Arcidiacono MV, Tebas P, Yarasheski KE, Dusso AS. HIV-protease inhibitors impair vitamin D bioactivation to 1,25-dihydroxyvitamin D. AIDS. 2003;17(4):513-20.

23. Ellfolk M, Norlin M, Gyllensten K, Wikvall K. Regulation of human vitamin $\mathrm{D}(3)$ 25-hydroxylases in dermal fibroblasts and prostate cancer LNCaP cells. Mol Pharmacol. 2009;75(6):1392-99.

24. Allavena C Delpierre C, Rey D, Cuzin L, Duvivier C, Viget N, Guillot $\mathrm{P}$, et al. Effects of ARV on vitamin D concentration in HIVinfected patients: a large prospective cohort analysis. Abstracts from the $18^{\text {th }}$ Conference on Retroviruses and Opportunistic Infections Boston; MA. 2-11 February 27-March 2, 2011.

25. Ross AC, Judd S, Kumari M, Hileman C, Labbato D, Storer N, et al. Vitamin D is linked to carotid intima-media thickness and immune reconstitution in HIV-infected individuals. Antivir Ther. 2011;16(4):555-63.

26. Viard JP, Souberbielle JC, Kirk O, Reekie J, Knysz B, Losso M, et al. Vitamin D and clinical disease progression in HIV infection: results from the EuroSIDA study. AIDS. 2011;25(10):1305-15.

27. Schousboe JT, Shepherd JA, Bilezikian JP, Baim S. Executive summary of the 2013 International Society for Clinical Densitometry Position Development Conference on bone densitometry. J Clin Densitom. 2013;16(4):455-66.

28. Kiebzak GM, Binkley N, Lewiecki EM, Miller PD. Diagnostic agreement at the total hip using different DXA Systems and the NHANES III Database. J Clin Densit. 2007;10(2):132-7.

29. Dickinson S, Fantry LE. Use of dual-energy x-ray absorptiometry (DXA) scans in HIV-infected patients. J Int Assoc Provid AIDS Care. 2015;11(4):239-44.

30. Institute of Medicine (US). Committee for the Oversight of AIDS Activities. Confronting AIDS: Update 1988. Washington (DC): National Academies Press (US). Appendix B, CDC Classification System for HIV Infections and Revised Case Definition for AIDS. 1988.

31. World Health Organization (WHO). Physical status: the use and interpretation of anthropometry. Report of a WHO Expert Committee. Geneva: WHO; 1995.

32. Gunville CF, Mourani PM, Ginde AA. The Role of Vitamin D in Prevention and Treatment of Infection. Inflammation \& allergy drug targets. 2013;12(4):239-45. 
33. Cole AM, Cole AL. HIV-Enhancing and HIV-Inhibiting Properties of Cationic Peptides and Proteins. Viruses. 2017;9(5):1-12.

34. Hileman CO, Labbato DE, Storer NJ, Tangpricha V, McComsey GA. Is bone loss linked to chronic inflammation in antiretroviralnaive HIV-infected adults? A 48-week matched cohort study. AIDS. 2014;28(12):1759-67.

35. Dao CN. Low vitamin D among HIV-infected adults: prevalence of and risk factors for low vitamin D Levels in a cohort of HIVinfected adults and comparison to prevalence among adults in the US general population. Clin Infect Dis. 2011;52(3):396-405.

36. Holick MF, Binkley NC, Bischoff-Ferrari HA, Gordon CM, Hanley DA, Heaney RP, et al. Evaluation, treatment, and prevention of vitamin D deficiency: an Endocrine Society clinical practice guideline. J Clin Endocrinol Metabolic. 2011;96(7):1911-30.

37. Brown TT, Hoy J, Borderi M, Guaraldi G, Renjifo B,Vescini F. Recommendations for Evaluation and Management of Bone Disease in HIV. Clinical Infect Dis. 2015;60(8):1242-51.

38. Brown TT, Chen Y, Currier JS, Ribaudo HJ, Rothenberg J, Dubé MP, et al. Body composition, soluble markers of inflammation, and bone mineral density in antiretroviral therapy-naive HIV-1-infected individuals. AIDS. 2013;63(3):323-30.

39. Dolan SE, Kanter JR, Grinspoon S. Longitudinal analysis of bone density in human immunodeficiency virus-infected women. Endocrinol Metabol Clin. 2006;91(8):2938-45. 